\title{
From good and bad to can and must: subjective necessity of acts associated with positively and negatively valued stimuli
}

\author{
GUIDO PEETERS* \\ Catholic University of Leuven, Belgium
}

\begin{abstract}
In Study 1, 24 participants generated sentences expressing ways of dealing with positively and negatively valued noun stimuli (objects and humans). They were instructed to begin each sentence with One + auxiliary verb. The auxiliary was to be selected from a set including auxiliaries expressing high (must) and low (can) necessity. As predicted on the basis of a minimal nonsocial model of behavioral adaptation, higher necessity was associated with negative stimuli than with positive stimuli. In Study 2, this effect was replicated using trait adjectives as stimuli. Consistent with the model, the effect was produced by stimulus valences belonging to an approach-avoidance related evaluative dimension 'other-profitability'. However, additional effects, involving an alternative evaluative dimension 'selfprofitability', were not fully accounted for by the model. They suggested that genuine social factors were involved that, however, were only required to explain some marginal effects. Copyright (C) 2002 John Wiley \& Sons, Ltd.
\end{abstract}

Various authors have described asymmetries in the ways in which subjects deal with positively valued stimuli, such as liked people and objects, on the one hand, and negatively valued stimuli, such as disliked people and objects, on the other (Cacioppo, Gardner, \& Berntson, 1997; Kanouse \& Hanson, 1972; Higgins, 1998; Lewicka, 1988; Peeters, 1971; Peeters \& Czapinski, 1990; Reeder \& Brewer, 1979; Skowronski \& Carlston, 1989; Taylor, 1991). At least many of those positive-negative asymmetries can be reduced to a basic structural asymmetry between approach and avoidance dispositions which has survival value and which has been described on referring to a metaphorical fungus eater who survives only if he or she succeeds in (a) approaching (consuming) mushrooms and (b) avoiding (consumption of) lethal toadstools (Peeters, 1971; Peeters \& Czapinski, 1990).

Taking the perspective of evolutionary psychology, one can readily assume that the adaptive strategy of the fungus eater may have evolved in species with relatively low reproduction rates such as humans. Hence the validity of the model of the mushroom eater is not questioned. What can be questioned is the extent to which the model can account for the processing of positive and negative

*Correspondence to: Guido Peeters, Laboratory of Experimental Social Psychology, University of Leuven (KU Leuven), Tiensestraat, 102, B-3000, Leuven, Belgium. E-mail: guido.peeters@psy.kuleuven.ac.be 
stimuli in general. Evolutionary psychologists have warned against unwarranted generalization because psychological mechanisms are likely to be domain specific (Buss, 1997).

Neurophysiological evidence across species, reviewed by Cacioppo et al. (1997), argues for the generality of the positive-negative asymmetry phenomenon, but this generality could be questioned on social psychological grounds. Humans are not like solitary mushroom eaters lost in the wilderness. They are members of cooperating and rivaling groups and the natural wilderness has been transformed into a wilderness of culture. This state of affairs may involve different survival strategies involving social processes such as communication, competition, social norms, etc.

Nevertheless, the model of the mushroom eater should not be abandoned too soon. Because of its simplicity and self-evident character it should be considered as a parsimonious explanation whenever possible. In this way the model has proven useful to shed light on a wide variety of phenomena (Peeters, 1971; Peeters \& Czapinski, 1990). However, it can also be used to trace unknown phenomena. A case in point is the present study which aims at establishing some implications of the model regarding the experience of subjective necessities of actions elicited by positive and negative stimuli.

In order to establish the model's implications regarding subjective necessities, we should take into account that the model focuses on two fundamental survival needs represented respectively by the desire to obtain mushrooms and the desire to avoid toadstools. In his elaborate theories on selfregulation, Higgins (1998) has referred to these needs as nurturance and security. The point is that in order to survive, the fungus eater need not approach every mushroom in the world: it suffices to approach some of them, and if mushrooms abound, one can select for consumption just a few that fit one's taste without being necessarily the best ones. Accordingly Higgins (1998) assumes that the need for nurturance is relieved through the promotion of positive outcomes guided by 'ideals' that are maximal goals a person can pursue to a certain degree without having to attain them.

However, a similar freedom of choice does not exist with respect to toadstools: in order to survive, the fungus eater must either avoid consuming any lethal toadstool or at least control possible negative consequences. Accordingly Higgins (1998) assumes that the need of security is relieved through the prevention of negative outcomes guided by 'oughts' that are minimal goals a person must attain.

It is worth noting that, according to Higgins (1998), oughts are not limited to concerns with safety but include responsibilities and obligations as well. The latter belong to the social realm about which the question was raised whether it would still belong to the field of application of the model of the solitary mushroom eater. Apparently, an affirmative answer to this question would be in accordance with Higgins' theory, particularly with the assumed association of responsibilities and obligations with the need of security. Thus not only the principle of parsimony, but also the assumptions of Higgins' theory argue for the generality of the mushroom eater model.

One way to test implications of the model regarding subjective necessity is based on an examination of the auxiliaries people use in sentences associated with positive and negative noun stimuli. Specifically, it could be expected that negative nouns would stimulate the use of auxiliaries such as must that express higher necessity than auxiliaries such as can and may. The latter express affordances (Beauvois \& Dubois, 2000; Zebrowitz \& Collins, 1997) which are expected to be associated with positive nouns. If this hypothesis is confirmed it would indicate that the pattern of behavioral dispositions with respect to positive and negative stimuli exemplified by the fungus eater is not limited to stimuli with extreme consequences regarding life and death, but may generalize to positively and negatively valued stimuli in general. Such a finding would extend the model to higher 'social' levels of psychological functioning and, in this way, add not only to the ecological validity of the model but also to the internal validity of Higgins' (1998) theory. 
While there may be good theoretical grounds for associating high subjective necessity with acts elicited by negative stimuli, direct empirical evidence is still lacking. The reason may be that most of the potentially relevant research was done by experimenters who were interested in the question of how perceived acts relate to perceived dispositional stimuli such as traits of the actor (e.g. Reeder and Brewer, 1979; Trafimow and Trafimow, 1999), rather than in the question of how perceived acts relate to perceived affordances of the stimuli that elicited them. Exceptions may be studies on decision making dealing with decisions as actions elicited by particular stimulus situations.

Particularly Lewicka $(1997,1998)$ has provided extensive reviews of her own and others' research on reasoning and decision making in the light of behavioral-adaptive concepts that fit the model of the mushroom eater. In those studies subjective necessity was not directly handled as a dependent variable. However, indirect evidence about subjective necessity could be derived. For instance, Lewicka (1997) observed differences between the information searches preceding decisions to 'accept' and decisions to 'reject'. While the information search preceding acceptances was attuned to select a sufficiently good alternative — not necessarily the best - the information search preceding rejections was attuned to eliminate the objectively worst alternative. Thus, when asked to accept an alternative, participants may have felt free to choose which alternative to accept among several acceptable alternatives. However, when asked to reject an alternative, they seemed not to feel free to reject some sufficiently bad alternative. Instead they acted as if they felt urged to reject the worst alternative. These results, and other evidence reviewed by Lewicka, are consistent with the notion that positive stimuli are perceived as opportunities allowing for possible actions, and negative stimuli are perceived as cues for more necessary actions. However, the evidence remains indirect. Therefore more direct evidence is provided by the present studies.

\section{STUDY 1: THE NOUN STUDY}

The aim of Study 1 was to provide a straightforward test of the hypothesis that subjects accord higher necessity to acts associated with negative stimuli than to acts associated with positive stimuli. The stimuli used were nouns. An additional aim was to check the generality of the hypothesized phenomenon across social and non-social stimuli by using nouns designating humans and nouns designating non-human objects.

\section{Design and Method}

\section{Design}

The hypothesis was tested using a $2 \times 2$ within Ss design. The factors were 'Valence' of stimulus nouns (positive versus negative) and 'Reference' of stimulus nouns (object versus human). Valence was manipulated by presenting 20 positive and 20 negative stimulus nouns. Reference was manipulated by having half of the nouns representing humans (friend, sadist, etc.), the other half representing physical objects (gift, vomit, etc.). Thus there were 10 stimuli per cell of the $2 \times 2$ design. Participants were asked to generate for each stimulus a sentence describing a way of dealing with the stimulus. In order to assess subjective necessity associated with the described dealings, the participants were instructed to begin each sentence with the expression 'One _' in which participants were to fill in the blank with an auxiliary to be selected from a list including auxiliaries associated with high necessity ('One must...') and auxiliaries associated with low necessity ('One can ...'). 


\section{Auxiliaries and the Operationalization of Subjective Necessity}

The experiment was run in Dutch. Thus Dutch auxiliaries were used which do not have perfect English analogs. Three auxiliaries were used, each of which could be modified by a negation to result in six alternatives: two expressing low necessity, three high necessity, and one ambiguous case.

Low necessity is expressed by Men kan and Men mag, which are translated respectively as One can and One may. Taken together, kan and mag cover about the same range of meanings as can and may, but there are no exact one-to-one relationships between the Dutch and English terms. For instance mag communicates exclusively the idea of permission which is only part of the meaning range of may.

High necessity is expressed by Men moet. It is translated One must but conveys also necessity by obligation (one has to, one ought). High necessity may also be conveyed by the negations of the low necessity auxiliaries kan and mag, henceforth referred to as negative can and negative may. ${ }^{1}$

Finally, the negation of Men moet, referred to as negative must, is totally ambiguous in Dutch: exactly the same expression can be used to convey that one must not enter (low necessity to enter) as to convey that one should not enter (high necessity to stay outside).

\section{Participants and Procedure}

Twenty-four (11 male and 13 female) Dutch-speaking participants aged between 16 and 30 years were recruited using a snowballing procedure: I started with some students and faculty staff and asked them to introduce me to some of their acquaintances. It was ascertained that participants were not acquainted with the theoretical background and specific aims of the study. They were individually invited to complete a questionnaire presented as a tool for composing a sample of ordinary sentences. Upon completion of the questionnaire, the participant was debriefed.

\section{Materials}

The questionnaire consisted of a list of 40 nouns with sufficient open space after each noun to write a sentence. The order of presentation was random and different for each participant. The nouns were drawn from the standard list of Hermans and De Houwer (1994) that provides average evaluative ratings of 740 Dutch words on a scale ranging from 1 (most negative) to 7 (most positive). The 10 most positive and the 10 most negative nouns designating humans were selected. Then 20 object names were selected in a way as to have each human matched with an object of approximately the same valence. Positive valences ranged from 6.61 to 4.94; negative valences from 1.48 to 2.77 . The following nouns were used. They are translated from Dutch and ordered from most positive to most negative. Positives are: friend, present, bouquet, child, toddler, chocolate, girl, palm-tree, woman, cake, house, singer, student, book, man, tree, baker, clothes, clown, room. Negatives are: cigarette, Mongol, knives, soldier, disabled, hooker, rubbish, excrement, refuse, disease-germ, thief, revolver, virus, sadist, hostage, vomit, gangster, tyrant, drugs, paedophilic.

The list of nouns was preceded with a brief introduction in Dutch inviting the participant to note for each noun a behavioral act one can, must or may perform with respect to the noun's referent. It was

\footnotetext{
${ }^{1}$ Nevertheless, some ambiguity may be involved in that, at least in Dutch, the negative particle can either modify the auxiliary or the main verb. For instance, the Dutch language does not discriminate between 'One cannot enter', signifying that one must stay outside (high necessity), and 'One can not enter' signifying that one can stay outside (low necessity). However, the second interpretation is rather uncommon and would be experienced as a figure of speech. Hence, it is reasonable to categorize 'negative can' and 'negative may' as expressions of high necessity, though with some reservation.
} 
stressed that the participant was expected to write sentences beginning with either One can, or One must, or One may. An example was added explaining that if the stimulus noun was 'closed door' possible responses could be: 'One must knock on it; one may not pass by it; one can open it'.

\section{Results and Discussion}

Twenty-four participants produced 40 sentences each, which resulted in 960 sentences. A decision was made not to rely on subjective estimations of necessity expressed by sentence contents. Instead I simply counted how often can, may, must, and their negations were used. No less than 945 sentences (98.4\%) were suited for the analysis.

For each participant the frequencies of the use of the six categories (can, may, must, and their negations) were counted per condition of the $2 \times 2$ design. In this way each participant yielded four sets (one set per condition) of six frequency scores (one score per auxiliary category) and within each set, the six scores were ipsative because they summed to a constant $N=10$, being the number of sentences per condition. In order to be able to remove decimal points from mean scores, without producing large rounding errors, the frequency scores were transformed into percentages. Each percentage relative to an auxiliary represented the number of sentences in which the auxiliary was used out of the maximal number of sentences in which the auxiliary could have been used. For instance if a participant used can in two out of the 10 sentences produced in one condition, the participant's percentage score of can for that condition amounted to 20 .

The scores relative to the six categories of auxiliaries were subjected to a MANOVA with auxiliaries as dependent variables.

There was a significant main effect of Valence, $F(6,18)=13.66, p<0.001$. It was not qualified by an interaction with Reference, which suggests a robust effect that generalizes across actions relative to both humans and objects. In order to specify the nature of the significant effect, univariate ANOVAs were applied to separate auxiliaries. The results are presented in Table 1 . They are in perfect agreement with the hypothesis. Compared with negative stimuli, positive stimuli elicited systematically more sentences introduced with One can or One may that expressed relatively low subjective necessity. Conversely, the negative stimuli elicited more sentences introduced with auxiliaries such as

Table 1. Study 1. Percentages of sentences marked by auxiliaries expressing different degrees of necessity as a function of the valence of the noun stimuli that elicited the sentences

\begin{tabular}{|c|c|c|c|c|c|}
\hline \multirow[b]{2}{*}{ Auxiliaries } & \multirow[b]{2}{*}{$\begin{array}{c}\text { Total } \\
(n=960)\end{array}$} & \multicolumn{2}{|c|}{ Valence of stimuli } & \multirow[b]{2}{*}{$F(1,23)$} & \multirow[b]{2}{*}{$M S E$} \\
\hline & & $\begin{array}{l}\text { Positive } \\
(n=480)\end{array}$ & $\begin{array}{l}\text { Negative } \\
(n=480)\end{array}$ & & \\
\hline \multicolumn{6}{|l|}{ Low necessity } \\
\hline Can & 56 & 72 & 41 & $56.00 * * *$ & 4.13 \\
\hline May & 4 & 5 & 2 & $5.70 *$ & 0.97 \\
\hline \multicolumn{6}{|l|}{ High necessity } \\
\hline Must & 29 & 16 & 43 & $56.21 * * *$ & 3.04 \\
\hline Negative can & 2 & 1 & 4 & $6.82 *$ & 0.34 \\
\hline Negative may & 6 & 4 & 8 & $16.38 * * *$ & 0.34 \\
\hline \multicolumn{6}{|l|}{ Undecided } \\
\hline Negative must & 1 & 1 & 1 & 1.30 & 0.07 \\
\hline Failures & 2 & 2 & 1 & & \\
\hline
\end{tabular}

$* p<0.05, * * p<0.01, * * * p<0.001$. 
must expressing relatively high necessity. Can and must responses, which were probably the least ambiguous ones, accounted for no less than $85 \%$ of all responses. Together with the absence of a significant interaction effect, this adds to the validity of the hypothesis. Moreover the obtained valence effects were quite large with shifts from $72 \%$ to $41 \%$ for can, and from $16 \%$ to $43 \%$ for must. Apparently the differential use of can and must with respect to positive and negative issues constitutes a quite salient and robust psycholinguistic phenomenon that is consistent with the positive-negative asymmetry concept as it is represented by the model of the fungus eater.

In addition to the predicted effect, there was an unpredicted main effect of Reference, $F(6,18)=4.03, p<0.01$. It indicated that $c a n$ was used less frequently to qualify actions relative to humans than actions relative to objects while the use of the five other auxiliaries (including the negatives) showed the opposite pattern. As this effect is irrelevant to the hypothesis it will not be discussed further.

\section{STUDY 2: THE TRAIT STUDY}

Study 1 confirmed that subjective necessity is higher for acts elicited by negative stimuli than for acts elicited by positive stimuli. So far, evidence was limited to noun stimuli, but considering that the stimuli included humans one may expect that manipulating personality traits as stimuli would produce the same effects as the noun stimuli. In addition, trait stimuli were suited to explore the implications of a more differentiated concept of stimulus valence than the simple unidimensional contrast of positive versus negative valences. Vonk (1993) has reviewed evidence that the Implicit Personality Theory that underlies the processing of trait stimuli is largely consistent with a two-dimensional space model. When the axes that represent the dimensions are rotated, they define a variety of alternative dimensional structures each of which can be used to describe the same space. For instance, it is possible to rotate the dimensions in a way combining a general evaluative dimension with a presumed nonevaluative 'potency' dimension. However, an alternative set of dimensions, rotated $45^{\circ}$ away, involves two evaluative dimensions that correspond to the 'social' and 'intellectual' good-bad dimensions established by Rosenberg and his collaborators (e.g. Rosenberg \& Sedlak, 1972). In this way social psychologists have advanced various two-dimensional sets that in general, however, reduce to a likability-related dimension (sociability, morality, etc.) and a power-related dimension (self-confidence, competence, etc.).

In their elaboration of the positive-negative asymmetry concept, also Peeters and Czapinski (1990) have distinguished between a likability-related and a power-related trait dimension. The former has been referred to as Other-Profitability $(O P)$, the latter as Self-Profitability $(S P)$. Each dimension contrasts a positive versus a negative valence. Positive (versus negative) $O P$ traits are perceived as unconditionally advantageous (versus disadvantageous) for others rather than for the possessors of the traits. For instance, tolerance may appear unconditionally advantageous to others who deal with the tolerant person. The perceived advantage to the tolerant person, however, may depend on whether others are expected to reward rather than to abuse the person's tolerance. Analogously, positive (versus negative) $S P$ traits are perceived as unconditionally advantageous (versus disadvantageous) to the possessors of the traits rather than to others dealing with the possessors. For instance, being powerful may appear unconditionally advantageous to the powerful person, but the perceived advantage to others may depend on whether the powerful person is expected to help rather than to exploit the others.

Consider that a stimulus person can be approached or avoided by an other but not by him- or herself. It follows that the approach-avoidance tendencies under discussion should be restricted to the $O P$

dimension. Evidence was provided by Wentura, Rothermund, and Bak (2000). In a lexical decision 
task participants were instructed to respond to (meaningful) words and not to respond to (meaningless) nonwords presented on a screen. In one condition they responded by pressing a key, which was an approach-related motor response. In another condition they responded by withdrawing from a key, which was an avoidance-related motor response. Responses to positive $O P$ trait words were relatively faster in the press condition while responses to negative $O P$ trait words were relatively faster in the withdraw condition, and this valence effect was not obtained for $S P$ trait words. Apparently approach and avoidance responses were facilitated by $O P$ stimulus values but not by $S P$ stimulus values. Hence, the tendency to associate higher subjective necessity with actions elicited by negative than by positive stimuli might be restricted to stimuli contrasted within the $O P$ dimension.

There is evidence, however, that $S P$ traits may assume approach-avoidance related $O P$ values in certain conditions. For instance, powerful others marked by positive $S P$ are preferred over powerless others marked by negative $S P$ if they are perceived as friends (Peeters, 1992) or ingroup members (Phalet and Poppe, 1997) but not if they are perceived as enemies or outgroup members. Similar interactions between power-related and likability-related stimulus values are not uncommon in the research literature (e.g. Singh \& Teoh, 2000; Vonk, 1996; Wojciszke, Bazinska, \& Jaworski, 1998). Altogether they suggest that the degree of perceived likability or $O P$ is polarized by the presence of high power or positive $S P$ and reduced by the presence of low power or negative $S P$. The relevant point is that high $S P$ strengthens the implications of $O P$ and low $S P$ reduces them. Considering that (a) a main implication of $O P$ is its approach-avoidance incentive value, and (b) according to the model of the mushroom eater subjective necessity of responses is directly related to the avoidance incentive value of the eliciting stimulus (or inversely related to the stimulus' approach incentive value), the following hypothesis can be advanced. Subjective necessity of acts elicited by $O P$ traits is higher for negative than for positive $O P$, and this difference is most prominent if the traits' $S P$ value is positive and it is reduced if the $S P$ value is negative.

\section{Method}

\section{Participants}

Fifty-two Psychology freshmen (14 males and 38 females) of the University of Leuven volunteered to complete an anonymous 'psycholinguistic questionnaire' presented during a collective research session which was part of the regular undergraduate program.

\section{Questionnaire}

The questionnaire was identical to that from Study 1 except for the following points.

Instead of nouns, stimuli were phrases composed following the format 'somebody who is TRAIT', e.g. 'somebody who's industrious'. In this way 22 trait stimuli were presented in four balanced orders which varied across participants. They were preceded with the same introduction as in Study 1 except that the example of the 'closed door' was replaced with another example using as stimulus 'a child that is ill' and as possible answers: 'One must take care of it; one can call a doctor; one may coddle it'.

\section{Traits}

The traits were obtained from a previous study (Peeters, Cornelissen, \& Pandelaere, 'Approachavoidence values of target-directed behaviors elicited by target-traits: The role of evaluative 
trait dimensions', Submitted, 1999) in which $S P$ and $O P$ values of traits were determined using a matching method extensively described and discussed by Peeters (1992). Two traits were fillers, twenty traits being experimental stimuli. Each trait represented both a (positive or negative) $O P$ value and a (positive or negative) $S P$ value. In this way each trait could be assigned to one out of the four conditions of a $2 \times 2$ within participants design: (positive versus negative) $O P$ and (positive versus negative) $S P$. The following traits (translated from Dutch) were used across the four conditions: $(1)+O P /+S P$ : active, industrious, dynamic, calm, jolly; (2) $+O P /-S P$ : timid, simple, reserved, obliging, emotional; (3) $-O P /+S P$ : ambitious, self-interested, false, stingy, violent; (4) $-O P /-S P$ : unstable, stupid, childish, anguished, and irritating.

\section{Results and Discussion}

Fifty-two participants, who responded to the five adjectives involved in each condition of the $2 \times 2$ within-participants design, produced 1040 responses. Only five responses were rejected as failures because they could not be classified objectively on the basis of the presence of an auxiliary. As in Study 1, participants were scored for the use of the six categories (can, may, must, and their negations) by counting the number of sentences in which each category was used and the obtained frequencies were expressed as percentages of the maximal number of sentences in which the category could have been used. The results are presented in Table 2. As in Study 1, the data were subjected to a MANOVA with the six auxiliaries as dependent variables. There were significant main effects of $O P, F(6,46)=3.30, p<0.01$, and $S P, F(6,46)=4.98, p<0.001$, that, however, were qualified by the interaction between $O P$ and $S P$ predicted by the hypothesis, $F(6,46)=3.45$, $p<0.01$.

Table 2. Study 2. Percentages of sentences marked by auxiliaries expressing different degrees of necessity as a function of self- and other-profitable valences of trait stimuli and results of univariate ANOVAs of interaction effects

\begin{tabular}{|c|c|c|c|c|c|c|c|}
\hline \multirow[b]{2}{*}{ Auxiliaries } & \multirow[b]{2}{*}{$\begin{array}{c}\text { Total } \\
(n=1040)\end{array}$} & \multicolumn{2}{|c|}{$+S P$} & \multicolumn{2}{|c|}{$-S P$} & \multirow[b]{2}{*}{$F(1,51)$} & \multirow[b]{2}{*}{$M S E$} \\
\hline & & $\begin{array}{c}+O P \\
(n=260) \\
\end{array}$ & $\begin{array}{c}-O P \\
(n=260) \\
\end{array}$ & $\begin{array}{c}+O P \\
(n=260) \\
\end{array}$ & $\begin{array}{c}-O P \\
(n=260) \\
\end{array}$ & & \\
\hline \multicolumn{8}{|l|}{ Low necessity } \\
\hline Can & 41 & $55_{\mathrm{a}}$ & $33_{\mathrm{b}}$ & $36_{\mathrm{b}}$ & $39_{\mathrm{b}}$ & $17.73^{* * *}$ & 1.15 \\
\hline May & 11 & 17 & 13 & 7 & 8 & 1.58 & 0.44 \\
\hline \multicolumn{8}{|l|}{ High necessity } \\
\hline Must & 37 & $22_{a}$ & $42_{b}$ & $44_{b}$ & $39_{\mathrm{b}}$ & $16.61 * * *$ & 1.34 \\
\hline Negative can & 2 & 0 & 3 & 1 & 3 & 0.40 & 0.05 \\
\hline Negative may & 7 & 5 & 6 & 10 & 9 & 0.25 & 0.30 \\
\hline \multicolumn{8}{|l|}{ Undecided } \\
\hline Negative must & 2 & 1 & 2 & 2 & 2 & 0.59 & 0.07 \\
\hline Failures & $>0$ & $>0$ & $>0$ & 0 & $>0$ & & \\
\hline
\end{tabular}

$* p<0.05, * * p<0.01, * * * p<0.001$.

Note: $+O P$ and $-O P=$ Positive and Negative Other-Profitability,

$+S P$ and $-S P=$ Positive and Negative Self-Profitability.

Values marked with different subscript letters differ significantly within rows (Scheffé tests $p<0.01$ ). 


\section{The Interaction between Self- and Other-Profitability}

As shown in Table 2, univariate ANOVAs indicated that the significant interaction between $S P$ and $O P$ concerned sentences introduced with can and must that were no less than $78 \%$ of all sentences. The results presented for may, negative can, and negative may reflect the interaction as well, but none of the latter interactions is significant. One reason why these interactions did not reach significance may be the small response rates involved in the measures (respectively $11 \%, 2 \%$, and $7 \%$ ). In addition the interaction may have been counteracted by the strong interactions for can and must because the measures were ipsative. This means that in each condition the sum of measures across verbs was a constant that corresponded to the number of stimuli presented (100\%). Ipsative measures, such as percentages, are suited for analysis of variance but they have a negative average pairwise correlation (Greer and Dunlap, 1997). Hence the strong interaction effects obtained for can and must could have reduced the chance probability of obtaining similar interactions for the other auxiliaries.

The significant interactions for can and must were further explored using post hoc tests presented in Table 2. They show that the effect of $O P$ on subjective necessity is only significant if the $S P$ value of stimuli is positive. Consistent with the hypothesis, subjective necessity of acts elicited by $O P$ traits is higher for negative than for positive $O P$ if the traits' $S P$ value is positive. If $S P$ is negative the effect of $O P$ is reduced, as predicted. One peculiarity of the configuration of significant differences revealed by the post hoc tests is that the interaction between $S P$ and $O P$ is marked by outstandingly high can scores and outstandingly low must scores in one single condition $(+S P /+O P)$. In that condition participants were presented with traits suggesting that they were dealing with powerful good persons. In the other three conditions, subjective necessity is higher and quite similar across acts relative to presumed powerful bad persons $(+S P /-O P)$, powerless bad persons $(-S P /-O P)$, and powerless good persons $(-S P /+O P)$. Two possible explanations are considered below.

First, it is possible that the low subjective necessity of acts relative to a person is not always related to the absence of the need to avoid negative outcomes expected from a bad person. Alternatively, the necessity to engage in a particular act relative to a powerful good person may be low in that this person has a high potential for beneficial outcomes and is expected to produce them generously to the advantage of others anyway, without requiring necessary actions being undertaken by those others. In addition, the person's potential may allow for a wide range of alternative positive outcomes letting the others take their choices. In order to obtain positive outcomes from a good but powerless person more effort and appropriate action may be required resulting in a higher degree of subjective necessity. Moreover, the person's inability to produce positive outcomes may lead to a negative image making that the person is placed in the category of the bad people.

According to the second explanation, subjective necessity of acts relative to good and powerless persons would be high because of social or ethical norms. De Bruin and Van Lange (1999a, b) observed that the good-and-powerless elicits exploitation, and exploiting others is to be avoided because it's immoral. This explanation is not incompatible with the previous one. However, it does not fit the model of the solitary fungus eater that disregards social determinants such as social and ethical norms.

\section{Unexpected Effects of Self-Profitability}

The cell means in Table 2 show convincingly that the significant main effect of $O P$ is caused by the significant interaction pattern. However, this is not evident for the main effect of SP. Univariate ANOVAs indicated that this significant effect was due to outcomes regarding may, $F(1,51)=18.41$, $p<0.001, \quad M S E=0.42, \quad$ must $, \quad F(1,51)=9.08, \quad p<0.01, \quad M S E=1.32$, and negative may, 
$F(1,51)=7.22, p<0.01, M S E=0.27$. Cell means in Table 2 show that the significant main effect for must is caused by the significant interaction pattern. However, the effects for may and negative may, which involve $18 \%$ of the responses, are not qualified by significant interactions and may be genuine main effects.

If the absence of significant interactions for may and negative may would not be an artefact due to low response rates and ipsativity, we should take seriously the main effects and conclude that positive $S P$ stimuli elicited effectively more may and less negative may responses than negative $S P$ stimuli. In search for an explanation we may consider that in Dutch, may (mag) versus negative may (mag niet) expresses primarily permission versus forbidding. Hence the combined main $S P$ effects for may and negative may suggest that participants assume that more is allowed and less is forbidden when dealing with powerful persons than when dealing with powerless persons (15\% versus $7.5 \%$ may responses and $5.5 \%$ versus $9.5 \%$ negative may responses). This explanation is interesting because it corresponds to the second explanation advanced at the end of the previous section to account for the high necessity of acts obtained in the $-S P /+O P$ condition. According to that explanation the high necessity reflected coercive social and ethical norms regarding actions relative to the good and powerless. The present main effects suggest that similar norms may apply to the powerless in general. For instance, the powerless should be the object of special care the good ones being protected and the bad ones being reformed. An important implication of this explanation is that it involves duties or social obligations conceived as social determinants of behavior that are not covered by the model of the solitary fungus eater.

\section{GENERAL DISCUSSION}

The model of the fungus eater, as well as the concordant concepts of Higgins (1998), associate positive stimuli with affordances and negative stimuli with necessities. Hence they imply greater subjective necessity of actions elicited by negative stimuli than of actions elicited by positive stimuli. Consistently, in Study 1, strong evidence was obtained that verbs expressing relatively high necessity (e.g. must) are used more frequently in sentences concerning negative 'bad' humans and objects than in sentences concerning positive 'good' humans and objects. In the latter sentences verbs expressing low necessity (e.g. can) are dominant. In addition, Study 2, which focused on human stimuli, provided strong evidence that this effect is largely consistent with an approach-avoidance related concept of evaluative meaning that is presupposed by the model of the fungus eater as well as by Higgins' concepts. The stimulus valence effect on subjective necessity was only obtained for human stimuli that appeared to have sufficient power to make the good humans worth approaching and to necessitate avoidance or control of the bad humans.

However, some minor outcomes of Study 2, particularly the use of may and negative may, may challenge the role of approach-avoidance dynamics implied by both the model of the fungus eater and Higgins' theory. Apparently, necessities conceived as duties or obligations do not vary as a function of stimulus valences that reflect the approach-avoidance related contrast between 'good people' with a high potential to benefit others versus 'bad people' with a high potential to harm others. Rather than a likability-related dimension 'good-bad for others' $(O P)$, the stimulus valences that control obligation reflect a power-related 'good-bad for self' dimension $(S P)$. In this way verbs expressing permission or low obligation were used relatively more frequently in descriptions of acts relative to powerful persons than in descriptions of acts relative to powerless persons. In the latter descriptions verbs expressing high obligation were more frequent. Considering that duties and obligations are necessities based on social dynamics that are not captured by the nonsocial model of the fungus eater, the present results 
provide an interesting 'social' addition to the model. Taking into account that humans are assumed to be an utmost social species, it may surprise that this addition was suggested by only a marginal part of the data.

The dissociation of duties and obligations from the model of the fungus eater challenges Higgins' theory in which duties and obligations are tarred with the same brush as are security needs. Indeed, all of them are presented as dynamic forces focused on the avoidance or prevention of negative outcomes rather than on the approach or promotion of positive outcomes. This common prevention focus would be due to the selective use of avoidance learning in child rearing practices. Particularly, children would acquire abilities to ensure security by learning how to avoid being hurt, and they would acquire observance of duties and obligations by learning how to avoid punishments inflicted by the caretakers (Higgins, 1998). One could wonder why caretakers would use avoidance-based rearing practices to impart observance of duties and obligations. The reason may be that duties and obligations are crucial for the well-functioning of society. Thus they should be loaded with a high degree of subjective necessity. At this point the fungus eater may re-enter the scene. Indeed, avoidance-based practices may be most suited to make duties and obligations endowed with high subjective necessity because, following the model of the fungus eater, evolution has endowed avoidance behavior with greater subjective necessity than approach behavior.

The general conclusion of the present study may be that subjective necessities acquired through socialization (Higgins, 1998) are largely consistent with the nonsocial model of the fungus eater. This is so even though highly socialized activities are involved such as the use of verbs in sentences describing responses to social stimuli. Nevertheless, besides the overwhelming support for the model, some data urge future researchers to be aware of the distinction between security needs, which can be associated with the model of the fungus eater, and duties or obligations, which, at least partly, belong to a social realm that lies outside the model.

\section{ACKNOWLEDGMENTS}

The author gratefully acknowledges the valuable comments provided by Ellen de Bruin, Glenn Reeder, Roos Vonk and Bogdan Wojciszke.

\section{REFERENCES}

Beauvois JL, Dubois N. 2000. Affordances in social judgment: Experimental proof of why it is a mistake to ignore how others behave towards a target and look solely at how the target behaves. Swiss Journal of Psychology 59: 16-33.

Buss DM. 1997. The emergence of evolutionary psychology. In Evolutionary Social Psychology, Simpson JA, Kenrick DT (eds). Erlbaum: Mahwah, NJ; 387-400.

Cacioppo JT, Gardner WL, Berntson GG. 1997. Beyond bipolar conceptualizations and measures: The case of attitudes and evaluative space. Personality and Social Psychology Review 1: 3-25.

De Bruin ENM, Van Lange PAM. 1999a. Impression formation and cooperative behavior. European Journal of Social Psychology 29: 305-328.

De Bruin ENM, Van Lange PAM. 1999b. The double meaning of a single act: Influences of the perceiver and the perceived on cooperative behavior. European Journal of Personality 13: 165-182.

Greer T, Dunlap WP. 1997. Analysis of Variance with ipsative measures. Psychological Methods 2: 200-207.

Hermans D, De Houwer J. 1994. Affective and subjective familiarity ratings of 740 Dutch words. Psychologica Belgica 34: 115-139. 
Higgins TE. 1998. Promotion and prevention: Regulatory focus as a motivational principle. In Advances in Experimental Social Psychology (Vol. 30), Zanna MP (ed.). Academic Press: San Diego, CA; 1-46.

Kanouse DE, Hanson LR Jr. 1972. Negativity in evaluations. In Attribution: Perceiving the Causes of Behavior, Jones EE, Kanouse DE, Kelley HH, Nisbett RE, Valins S, Weiner B (eds). General Learning Press: Morristown, SD; 47-62.

Lewicka M. 1988. On objective and subjective anchoring of cognitive acts: How behavioral valence modifies reasoning schemata. In Recent Trends in Theoretical Psychology, Baker J, Mos LP, Rappard HV, Stam HJ (eds). Springer-Verlag: New York; 285-301.

Lewicka M. 1997. Is hate wiser than love? Cognitive and emotional utilities in decision making. In Decision Making: Cognitive Models and Explanations, Ranyard R, Crozier WR, Svenson O (eds). Routledge: London; 90-106.

Lewicka M. 1998. Confirmation bias: Cognitive error or adaptive strategy of action control? In Personal Control in Action. Cognitive and Motivational Mechanisms, Kofta M, Weary G, Sedek G (eds). Plenum Press: New York; 233-258.

Peeters G. 1971. The positive-negative asymmetry: On cognitive consistency and positivity bias. European Journal of Social Psychology 1: 455-474.

Peeters G. 1992. Evaluative meanings of adjectives in vitro and in context: Some theoretical implications and practical consequences of positive-negative asymmetry and behavioral-adaptive concepts of evaluation. Psychologica Belgica 32: 211-231.

Peeters G, Czapinski J. 1990. Positive-negative asymmetry in evaluations: The distinction between affective and informational negativity effects. In European Review of Social Psychology (Vol.1), Stroebe W, Hewstone M (eds). Wiley: Chichester; 33-60.

Phalet K, Poppe E. 1997. Competence and morality dimensions of national and ethnic stereotypes: A study in six Eastern-European countries. European Journal of Social Psychology 29: 703-723.

Reeder GD, Brewer MB. 1979. A schematic model of dispositional attribution in interpersonal perception. Psychological Review 86: 61-79.

Rosenberg S, Sedlak A. 1972. Structural representations of implicit personality theory. In Advances in Experimental Social Psychology (Vol. 6), Berkowitz L (ed.). Academic Press: New York; 235-297.

Singh R, Teoh JBP. 2000. Impression formation from intellectual and social traits: Evidence for behavioural adaptation and cognitive processing. British Journal of Social Psychology 39: 537-554.

Skowronski JJ, Carlston DE. 1989. Negativity and extremity biases in impression formation: A review of explanations. Psychological Bulletin 105: 131-142.

Taylor SE. 1991. Asymmetrical effects of positive and negative events: The mobilization-minimization hypothesis. Psychological Bulletin 110: 67-85.

Trafimow D, Trafimow S. 1999. Mapping perfect and imperfect duties onto hierarchically and partially restrictive trait dimensions. Personality and Social Psychology Bulletin 25: 686-695.

Vonk R. 1993. Individual differences and common dimensions in Implicit Personality Theory. British Journal of Social Psychology 32: 209-226.

Vonk R. 1996. Negativity and potency effects in impression formation. European Journal of Social Psychology 26: 851-865.

Wentura D, Rothermund K, Bak P. 2000. Automatic vigilance: The attention-grabbing power of approach- and avoidance-related social information. Journal of Personality and Social Psychology 78: 1024-1037.

Wojciszke B, Bazinska R, Jaworski M. 1998. On the dominance of moral categories in impression formation. Personality and Social Psychology Bulletin 24: 1251-1263.

Zebrowitz LA, Collins MA. 1997. Accurate social perception at zero acquaintance: The affordances of a Gibsonian approach. Personality and Social Psychology Review 1: 204-223. 
Copyright of European Journal of Social Psychology is the property of John Wiley \& Sons Inc. and its content may not be copied or emailed to multiple sites or posted to a listserv without the copyright holder's express written permission. However, users may print, download, or email articles for individual use. 